\title{
Ductile iron mechanical properties at intermediate temperatures: effect of Silicon and Pearlite content
}

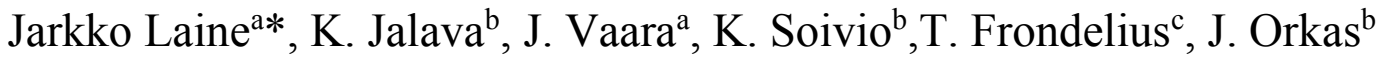 \\ ${ }^{a}$ Wartsila Oyj, Vaasa, Finland; ${ }^{b}$ Department of Mechanical Engineering, Aalto \\ University, Espoo, Finland; ${ }^{c}$ Materials and Mechanical Engineering, University of \\ Oulu, Oulu, Finland \\ *Järvikatu 2-4, FI-6500 VAASA; jarkko.laine@wartsila.com
}




\title{
Ductile iron mechanical properties at intermediate temperatures: effect of Silicon and Pearlite content
}

\begin{abstract}
The usage of ductile irons at thermo mechanically loaded components is increasing, necessitating more knowledge of material properties in elevated temperatures. A study of elevated temperature mechanical properties was done, investigating the effect of different pearlite fractions along with silicon content tests in fully ferritic microstructure. Effect of pearlite fraction and silicon content to tensile and yield strength were measured in different temperatures from room temperature up to $450^{\circ} \mathrm{C}$. Models were developed, based on those measurements. These resulting regression models were tested with data gathered from literature. These can be used in various design tools, such as FEM calculations and in the optimisation of thermally and cyclic loaded ductile iron components.
\end{abstract}

Keywords: ductile iron; mechanical properties; intermediate temperature; silicon; ferrite; pearlite

\section{Introduction}

Cast irons are classified by graphite structure: lamellar (grey), vermicular (compacted), spheroidal (ductile) and graphite free (white) irons (ASM). White cast irons are hard and brittle, and, for that reason, they are used only for special purposes. Ductile and grey cast irons are most commonly used irons today. Ductile iron production has steadily increased and its importance has increased. Production in 1970 was 0.3 million tons and in 2018 it was 90 times higher, 128.1million tons being about 25 $\%$ of total casting production[1-3]. Development of ductile iron started at the end of the 1930 's. It was noted that cast iron with nodularised graphite directly on cast would give benefits compared to malleable iron with long heat treatments. In England H, Morrough studied graphite formation mechanism and found a ductile iron manufacturing method with mischmetal contained Cerium. In the USA Nickel Ltd studied possibilities to 
replace $\mathrm{Ce}$ with $\mathrm{Mg}$ in white cast irons. They found a method of making ductile iron adding nickel-magnesium alloy with $15 \%$ of $\mathrm{Mg} .[4]$

The ductile iron microstructure consists of matrix and graphite nodules. The share of graphite in the image of the microstructure is typically around $10-12 \%$ of the surface area according to the carbon content and the microstructure. If the nodularity is good and there is no degenerated graphite, the decrease of the tensile strength is profractional to the surface area ratio of the graphite in tension. If there are imperfect nodules, such as coarse (chunky) graphite, the mechanical properties, especially elongation, degrease.[58]

The structure of the matrix has the greatest impact on the properties of the material. It is ferrite, pearlite, or their compound on normal ductile irons. Ferrite is a body centred cubic iron, so-called $\alpha$-iron. It is a layered structure composed of ferrite and $\mathrm{Fe}_{3} \mathrm{C}$ cementite. Cementite has a very high tensile strength of 4600-8000 MPa [9]. The tensile strength values of fully pearlitic ductile iron can be up to $1000 \mathrm{MPa}$. It stays stable up to $450-500^{\circ} \mathrm{C}$ depending on the alloy. At higher temperatures, pearlite begins to transform into ferrite and graphite [10]. To achieve better mechanical properties, some pearlite promoter is added to the melt. Copper is the most common of that increases the pearlite fraction and strengthens the matrix [11]. Copper alloying has no practical effect on ferrite strength properties [12]. For pearlitisation there can be used other alloying elements adding, like tin ( $\mathrm{Sn})$. Manganese $(\mathrm{Mn})$ is works as pearlite stabilizer, it is coming from raw materials. In that reason it's levels at ferritic grades, should be keep under $0.35 \% .[13]$

Silicon ( $\mathrm{Si}$ ) is one of the main constituents in cast irons, working as ferrite stabilizer. Silicon alloying improves the mechanical properties of ferrite by solution strengthening. High silicon, so called solution strengthened ferritic (ssf) was developed in Sweden in 
the late 1990s and was first added to the national SS standard in 1998, ISO 1083 in 2004 and EN 1563 in 2011 [14]. For this reason, the Si alloy has been studied extensively, especially with a Si content of 3.5 to $5 \%$. The addition of $4 \%$ silicon increases the mechanical properties significantly, the maximum tensile strength up to $550 \mathrm{MPa}$ from $400 \mathrm{MPa}$ standard (Si content 2-2.5\%). The addition of 5\% Si increases maximum strength up to $650-700 \mathrm{MPa}$. When it exceeds $5.5 \%$, the strength values decrease dramatically. Some results of the Si effect on the tensile strength at room temperature are shown in figures 8 and 9.[12,15-19] Iron-based metals exhibit hardening effects with certain combinations of temperature and strain rate. This effect is called dynamic strain aging (DSA). In tensile tests it can be seen as striations in the stress-strain curves [20]. This phenomenon has been attributed to be an interaction between moving dislocations and solute elements like carbon or nitrogen and occurs at the temperature range of $100-300^{\circ} \mathrm{C}$.[21] It is also observed on ferritic[20], ferriticpearlitic and pearlitic ductile cast irons [22].

The use of ductile irons is increasing in engine components, where the materials are under thermal and mechanical loads. For that reason, it is very important to know tensile properties at elevated temperatures. There is a lot of data available at room temperature, like but obvious lack of consistent data at elevated temperatures. $[12,15,16,18,23-26]$ The studied temperature ranges from room temperature to $450^{\circ} \mathrm{C}$ is wide enough for the engineering use. In this study, the effect of different pearlite fractions and different silicon contents in fully ferritic microstructure were investigated.

\section{Experimental procedure}

Testing in this study consist of two parts; a) how the silicon content in the ferritic structure affects the tensile and yield strength and, b) how the pearlite fraction in the microstructure affects the same, in the temperature range from room temperature to 
$450^{\circ} \mathrm{C}$. Different pearlite fractions are achieved through heat treatments. The reason for this is to minimize the variation that originates from the casting process, such as alloying elements, grain size and graphite structure.

Effect of pearlite was studied with commonly used grade EN-GJS-500-7 (EN 1563) (1). In this grade, $\mathrm{Cu}$ is used as a pearlitizing element. It gives good mechanical properties in as-cast condition, but they can vary within the casting due to the solidification and cooling rate.

Studying the effect of silicon concentration on fully ferritic iron was used in addition to GJS-500-7 high silicon iron grades EN-GJS-500-14 (2) and EN-GJS-600-10 (3) and an experimental low silicon content ductile iron, so-called GJS LowSi (4). The compositions are shown in table 1.

Samples were made as separately cast test bars $\varnothing 25 \mathrm{~mm}$ and length $165 \mathrm{~mm}$ according to EN 1563:2011 (type b: figure 3). Melting was done with large medium frequency furnace as a part of normal foundry process. The magnesium treatment was carried out with a sandwich method and the pouring temperature was $1360^{\circ} \mathrm{C}$.

EN-GJS-500-7 samples were heat treated to different ferrite-pearlite microstructures. All heat treatments started with austenization at $900{ }^{\circ} \mathrm{C}$. Batch 1 was slowly cooled at $20^{\circ} \mathrm{C} /$ hour to obtain a completely ferritic structure with relatively high copper content. Batch 2 and 3 were ferritized at $690^{\circ} \mathrm{C}$ for 4 hours (batch 2) and 0.5 hours (batch 3) to reach intermediate pearlite fractions. Batch 4 was cooled in air after austenization to reach a fully pearlitic structure. The heat treatments and microstructures are shown in table 2.

Microstructural image analysis was performed after heat treatment to calculate ferritepearlite fractions and to check for unwanted changes in graphite morphology. Samples were ground and polished, the graphite fraction was analysed from images of unetched 
samples and absolute ferrite-pearlite area fractions from Nital-etched samples together with the information of graphite area fraction from the previous step. In the analysis, only the matrix was taken into account. Fully pearlitic matrix is labelled as $100 \%$ pearlitic, even as about $10 \%$ of microstructure consists of graphite nodules. Pearlite fraction of samples are given in Table 2. Images of the corresponding microstructures are shown in Figures 1a-d.

The mechanical tests were carried out with a standard $200 \mathrm{kN}$ MTS machine with RT, $100,250,350$ and $450^{\circ} \mathrm{C}$ test temperatures for GJS-500-7 and GJS-LowSi. Materials GJS-500-14 and GJS-600-10 were tested at Rt, $350,400,450^{\circ} \mathrm{C}$. The geometry of the test bar is shown in Figure 2.

\section{Results}

Effect of pearlite fraction on tensile and yield strength at different temperatures is shown in Figures 3 and 4. Testing temperature and pearlite fraction has a clear effect on mechanical properties. Maximum tensile strength of $890 \mathrm{MPa}$ was achieved with a fully pearlitic structure at room temperature. When the temperature rises to $450^{\circ} \mathrm{C}$, it drops by $30 \%$ to $616 \mathrm{MPa}$. The fully ferritic grade has a tensile strength of $418 \mathrm{MPa}$ at room temperature and is $25 \%$ lower, $316 \mathrm{MPa}$, at $450^{\circ} \mathrm{C}$. Intermediate structure properties fall between them. The yield strength varies from a fully pearlitic $498 \mathrm{MPa}$ to a fully ferritic $275 \mathrm{MPa}$ at room temperature. It decreases by $27 \%, 365 \mathrm{MPa}$ with fully pearlitic and by $20 \%, 230 \mathrm{MPa}$, with fully ferritic grades at $450^{\circ} \mathrm{C}$.

The dynamic strain aging can be seen well in tensile strength at 250 and $350^{\circ} \mathrm{C}$. In this study, the grade of $25 \%$ pearlite showed the largest DSA effect; the maximum tensile strength of $535 \mathrm{MPa}$ reached at $350^{\circ} \mathrm{C}$, compared to $475 \mathrm{MPa}$ at room temperature. Yield strength results do not give a clear indication of the DSA, except in the case of 
fully pearlitic grade showing increase of approximately $15 \%$ at $350^{\circ} \mathrm{C}$, compared to linear trend made with measurement points out of DSA region.

The effect of silicon content on tensile and yield strength is shown in Figures 5 and 6. The tensile strength of high silicon (4.37\%), material 3, iron decreases by $30 \%$ from 654 $\mathrm{MPa}$ at $\mathrm{Rt}$ to $415 \mathrm{MPa}$ at $450^{\circ} \mathrm{C}$. The drop of material $1(2.3 \% \mathrm{Si})$ is $20 \%$ and low silicon, material 4 , is $17 \%$. In general, the strengthening effects of pearlite and silicon decrease at higher temperatures.

The existence of dynamic strain aging can be seen in tensile strength at all pearlite shares and silicon concentrations, except for material $4(1.5 \% \mathrm{Si})$. No effect of DSA to yield strength is evident in these tests.

Modelling was done using Origin software, with a non-linear surface fitting that maximizes R-Square value. Polynomial surface of order 3 was the lowest that provided a reasonable fit with a constant shape.

Effect of pearlite share to tensile and yield strength are:

$$
\begin{aligned}
& U T S(P e \%)=0.0019(P e \%)^{3}-0.200(P e \%)^{2}+7.09(P e \%)-1.38 E^{-5}(t)^{3}+ \\
& 0.00823(t)^{2}-1.36(t)+470 \\
& \text { Pe\% } \varepsilon[0,100], \mathrm{t} \varepsilon[20,450] \text { Eqn. } 1 \\
& Y S(P e \%)=0.0006(P e \%)^{3}-0.059(P e \%)^{2}+1.98(P e \%)-3.34 E^{-6}(t)^{3}+ \\
& 0.00236(t)^{2}-0.614(t)+291 \mathrm{Pe} \% \varepsilon[0,100], \mathrm{t} \varepsilon[20,450] \text { Eqn. } 2
\end{aligned}
$$


With R-square values of 0.962 for UTS and 0.958 for YS

Effect of silicon concentration to tensile and yield strength are:

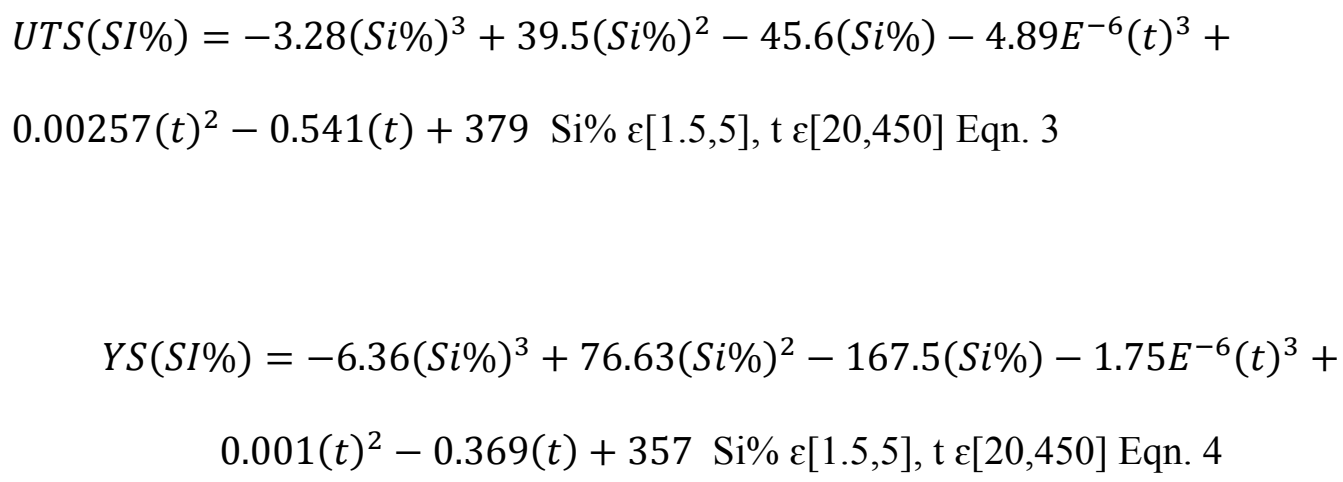

With R-square values of 0.940 for UTS and 0.98 for YS.

Equations 1, 2, 3 and 4 can be combined following way:

$U T S(t o t)=U T S[P e \%, U T S(S i \%)]$ Eqn. 5

and

$Y S($ tot $)=Y S[P e \%, Y S(S i \%)]$ Eqn. 6

$$
\begin{aligned}
& U T S(\text { tot })=0.0019(P e \%)^{3}-0.200(P e \%)^{2}+7.09(P e \%)-1.38 E^{-5}(t)^{3}+ \\
& 0.00823(t)^{2}-1.36(t)+U T S(S i) \text { Eqn. } 7
\end{aligned}
$$

$$
\begin{aligned}
& \operatorname{UTS}(\text { tot })=0.0019(P e \%)^{3}-0.200(P e \%)^{2}+7.09(P e \%)-3.28(S i \%)^{3}+ \\
& 39.5(S i \%)^{2}-45.6(S i \%)-1.87 E^{-5}(t)^{3}+0.0108(t)^{2}-1.90(t)+379
\end{aligned}
$$


$\mathrm{Pe} \% \varepsilon[0,100], \mathrm{Si} \% \varepsilon[0,5], \mathrm{t} \varepsilon[20,450]$ Eqn. 8

and

$$
\begin{aligned}
& Y S(\text { tot })=0.0011(P e \%)^{3}-0.108(P e \%)^{2}+2.88(P e \%)-3.34 E^{-6}(t)^{3}+ \\
& 0.00236(t)^{2}-0.614(t)+Y S(S i \%) \text { Eqn. } 9
\end{aligned}
$$

$$
\begin{aligned}
& Y S(\text { tot })=0.0011(P e \%)^{3}-0.108(P e \%)^{2}+2.88(P e \%)-6.36(S i \%)^{3}+ \\
& 76.63(S i \%)^{2}-167.5(S i \%)-2.62 E^{-6}(t)^{3}+0.00923(t)^{2}-1.729(t)+357 \quad \mathrm{Pe} \% \\
& \varepsilon[0,100], \mathrm{Si} \% \varepsilon[0,5], \mathrm{t} \varepsilon[20,450] \quad \text { Eqn. } 10
\end{aligned}
$$

\section{Discussion}

The tensile properties of ductile iron with different Si content and pearlite fraction at room temperature are extensively studied. More alloyed ductile irons are studied for use in exhaust manifolds in high temperature areas (over $\left.600^{\circ} \mathrm{C}\right)[11,27]$. There has been a lack of data for un-alloyed ductile irons in the intermediate temperature range, which this work fills.

UTS can be combined by replacing the constant value of the effect of pearlite equation (Eqn. 1) with the silicon effect equation (Eqn. 3). In this case, the possible ferrite strengthening effect in pearlite and its effect to pearlite strength is not considered. The tensile strength of the fully pearlitic steel is $1105 \mathrm{MPa}$ with $0.01 \% \mathrm{Si}$ [28] practically fully pearlitic (99\% of matrix) ductile iron $1002 \mathrm{MPa}$, with $12 \%$ graphite nodules and $2.7 \%$ silicon [25]. According to these values, when it is assumed that the graphite 
nodule functions as a void in a tensile test, the effective error is at maximum $1.5 \%$ in a fully pearlitic structure. No data is available on the effects of silicon on the pearlite strength values and no measurements to investigate that effect is made in this study.

These equations can be tested at room temperature with the values collected from literature. Figures 6 and 7 are effects of pearlite content to tensile and yield stress. When a power of order 3 polynomial is fitted to these values result is the following equation:

$\operatorname{UTS}($ measured $)=0.00176(P e \%)^{3}-0.205(P e \%)^{2}+8.386(P e \%)+387$ Eqn. 11

When this equation (11) is used with values shown in Fig. $6, \mathrm{r}^{2}$ value is 0.919 compared calculated values. With the model developed in this work (Eqn. 8) with the same data ${ }^{2}$ value is 0.923 . The model (Eqn. 8) developed from measurements is in good agreement with the values collected from literature.

Verification of yield strength model was done similarly, comparison to values shown in fig. 7. Equation of values' $3^{\text {rd }}$ power trendline is:

$Y S($ measured $)=0.0009(P e \%)^{3}-0.0989(P e \%)^{2}+3.424(P e \%)+269($ Eqn. 12$)$

When this equation [11] is used with values shown in Fig. $6, \mathrm{r}^{2}$ value is 0.855 compared calculated values. With the model developed in this work (Eqn. 9) with the same data $\mathrm{r}^{2}$ value is 0.911 . The model (Eqn. 8) developed from measurements is in good agreement with the values collected from literature.

Figures 8 and 9 are showing comparison to values, with different Si content and fully ferritic structure, collected from literature. The standard deviation of tensile strength 
values calculated with model (Eqn. 8) is 0.923 and 0.900 when values are compared to their polynomial fitting. Similar values for yield strength are 0.967 (Eqn. 10) and 0.968 (polynomial fit).

Usable Silicon range 1.5 to $5 \%$ of this model is based on measurements and foundry practices. Nodularisation and inoculation agents are containing high amounts of $\mathrm{Si}$, and they are limiting practical Si-content. Due to silicon's high tendency to promote ferrite, with high silicon contents, there is no pearlite in the microstructure with standard practices. Maximum temperature of this model is $450^{\circ} \mathrm{C}$.

In this study, the size of the test bar has been optimal for a good nodularization and microstructure, so the model does not take into account the possible effects of grain size and deviation of the graphite structure, which can affect material properties.

Solution strengthen grades are from another measurement series, and they are incomplete for this study. This causes some inaccuracy for high Si content at 200-300 C area.

The model developed in this study has a good accuracy when tested with the values from the literature. At elevated temperatures thermal conductivity and DSA effect has a big influence on the material behaviour. Model is developed for finite element analysis of components with thermal and mechanical load.

\section{Conclusions}

The effect of pearlite fraction and silicon content in ductile irons on tensile and yield strength was studied from room temperature to $450^{\circ} \mathrm{C}$.

- Increase of pearlite fraction increases strength properties in all studied temperatures 
- Increase of silicon content increases strength properties in all studies temperature areas.

- DSA can be seen all pearlite fractions and silicon content.

- Based on those studies models for tensile (Eqn. 8) and yield (Eqn. 10) strength was developed. Models were verified with values from literature, and they worked well.

Table 1: Chemical composition of studied alloys. Matrix microstructure of alloys 2-4 is fully ferritic. Alloy 1 microstructure depends heat treatments in table 2 .

Table 2: Heat treatments and microstructure after heat treatment.

Fig 1: Microstructures of studied pearlite fractions (a $0 \%$, b 25\%, c 70, and d 100\%)

Fig 2: Test bar critical dimensions

Fig 3: Tensile strength of results with different pearlite fractions (Pe\%).

Fig 4: Yield strength results with different pearlite fractions ( $\mathrm{Pe} \%)$.

Fig 5: Effect of silicon (Si\%) to tensile strength values.

Fig 6: Effect of silicon ( $\mathrm{Si} \%)$ to yield strength over different temperatures 
Fig 7: Ductile iron tensile strength as a function of pearlite amount values from literature [23-25.29]. The continuous line is the trend line of literature values and the dotted lines are model with 2 different silicon contents. These contents are presenting highest (2.77\%) and lowest (1.98\%) values from literature.

Fig 8: Ductile iron yield strength as a function of pearlite amount values from literature $[23-25,29]$. The continuous line is the trend line of literature values and the dotted lines are model with 2 different silicon contents. These contents are presenting highest $(2.77 \%)$ and lowest $(1.98 \%)$ values from literature

Fig 9: Ductile iron tensile strength as a function of Si content values from literature [12, 15-17, 19], with trendline (continuous) and model (Eqn. 8) (dotted) line up to 5\% of silicon.

Fig 10: Ductile iron tensile yield as a function of Si content amount values from literature [12,15-17,26] with trend line (continuous) and model (Eqn. 10)(dotted line).

Reference

1. Fatahalla N. Metallurgical parameters, mechanical properties and machinability of ductile cast iron. Journal of Materials Science (UK). 1996;31(21):5765-5772.

2. Liu Y. Effect of graphite morphology on the tensile strength and thermal conductivity of cast iron. Mater Charact. 2018;144:155-165. doi: 10.1016/j.matchar.2018.07.001.

3. Miller Liam, Vakili Ray, Onge Jason St, Wang Zhen. Census of world casting production: Worldwide casting procution growth slowed but still reported a $2.6 \%$ increase in 2018. Mod Cast. 2019;109(12):26-28. 
4. Autere E, Ingman Y, Tennilä P. Valimotekniikka. Helsinki Finland: Insinööritieto Oy; 1982:196-202.

5. Ferro P. Fatigue properties of ductile cast iron containing chunky graphite. Materials Science \& Engineering A. 2012;554:122-128. doi: 10.1016/j.msea.2012.06.024.

6. Foglio E. Fatigue design of heavy section ductile irons: Influence of chunky graphite. Mater Des. 2016;111:353-361. doi: 10.1016/j.matdes.2016.09.002.

7. Mourujärvi A. Influence of chunky graphite on mechanical and fatigue properties of heavy- section cast iron. Fatigue \& Fracture of Engineering Materials \& Structures. 2009;32(5):379-390. doi: 10.1111/j.1460-2695.2009.01337.x.

8. Ruff G. Relationship between mechanical properties and graphite structure in cast irons. II.--ductile iron. Mod Cast. 1980;70(7):70-74.

9. Bhadeshia, H. K. D. H. Cementite. International Materials Reviews. 2019:1-27. doi: 10.1080/09506608.2018.1560984.

10. Ghodrat S. Volume expansion of compacted graphite iron induced by pearlite decomposition and the effect of oxidation at elevated temperature. Oxidation Metals. 2013;80(1):161-176. doi: 10.1007/s11085-013-9406-y.

11. ASM handbook .9th edition ed. Ohio, USA: American Society for Metals; 1978;Properties and Selection: Irons and Steels.

12. Alhussein A. Influence of silicon and addition elements on the mechanical behavior of ferritic ductile cast iron. Materials Science \& Engineering A. 2014;605:222-228. doi: 10.1016/j.msea.2014.03.057. 
13. Brown J. The foseco foundryman's handbook, 10th edition.(book).; 1994.

https://aalto.finna.fi/PrimoRecord/pci.proquest24302016.

14. Larker R. Solution strengthened ferritic ductile iron ISO 1083/JS/500-10 provides superior consistent properties in hydraulic rotators - solution strengthened ferritic ductile iron ISO 1083/JS/500- 10 provides superior consistent properties in hydraulic rotators. China Foundry. 2009;6(4):343-351.

15. González-Martínez R. Effects of high silicon contents on graphite morphology and room temperature mechanical properties of as-cast ferritic ductile cast irons. part I microstructure. Materials Science \& Engineering A. 2018;712:794-802. doi:

10.1016/j.msea.2017.11.050.

16. Ikeda T. Infiuence of silicon content, strain rate and temperature on toughness and strength of solid solution strengthened ferritic ductile cast iron. Materials Transactions. 2016;57(12):2132-2138. doi: 10.2320/matertrans.F-M2016832.

17. Unkic F. Vpliv silicija in bora na natezne lastnosti duktilne litine/ the influence of silicon and boron on tensile properties of ductile iron. Livarski Vestnik. 2012;59(2):6879.

18. Wang Z. Effect of shrinkage porosity on mechanical properties of $f$ erritic ductile iron. China Foundry. 2013;10(3):141-147..

19. Weiß P. Mechanistic approach to new design concepts for high silicon ductile iron. Materials Science \& Engineering A. 2018;713:67-74. doi: 10.1016/j.msea.2017.12.012.

20. Mouri H. Effect of dynamic strain aging on isothermal (473 K) low cycle fatigue of ferritic ductile cast iron. Materials Transactions. 2009;50(8):1935. 
21. Caillard D. An in situ study of hardening and softening of iron by carbon interstitials. Acta Materialia. 2011;59(12):4974-4989. doi:

10.1016/j.actamat.2011.04.048.

22. Jalava K. Effect of silicon and microstructure on spheroidal graphite cast iron thermal conductivity at elevated temperatures. International Journal of Metalcasting. 2018;12(3):480-486. doi: 10.1007/s40962-017-0184-1.

23. Hafiz M. Mechanical properties of SG-iron with different matrix structure. J Mater Sci. 2001;36(5):1293-1300.

24. Canzar P. Microstructure influence on fatigue behaviour of nodular cast iron. Materials Science and Engineering A: Structural Materials: Properties, Microstructures and Processing. 2012;556(C):88-99. doi: 10.1016/j.msea.2012.06.062.

25. Kubota S. Effect of microstructure on mechanical properties and machinability of spheroidal graphite cast iron. Chuzo Kogaku (Journal of Japan Foundry Engineering). 2013;85(8):489-496. doi: 10.11279/jfes.85.489.

26. Weiß P. Mechanistic approach to new design concepts for high silicon ductile iron. Materials Science \& Engineering A. 2018;713:67-74.. doi: 10.1016/j.msea.2017.12.012.

27. Chang C. The study on the microstructures and mechanical properties of high silicon ductile irons alloyed with molybdenum. Journal of Taiwan Foundry Society. 2007;33(3):42-50. https://aalto.finna.fi/PrimoRecord/pci.proquest30085122.

28. Toribio J. Influence of microstructure on strength and ductility in fully pearlitic steels. Metals. 2016;6(12):318. doi: 10.3390/met6120318. 
29. Dix L. Static mechanical properties of ferritic and pearlitic lightweight ductile iron castings. Transactions of the American Foundry Society. 2003;111:895-910. 


$\begin{array}{lllllllll}\text { Material } & \mathrm{C} \% & \mathrm{Si} \% & \mathrm{Mn} \% & \mathrm{P} \% & \mathrm{~S} \% & \mathrm{Sn} \% & \mathrm{Cu} \% & \mathrm{Mg} \% \\ 1 & 3.40 & 2.30 & 0.40 & 0.030 & 0.008 & 0.009 & 0.24 & 0.043 \\ 2 & 3.45 & 3.68 & 0.35 & 0.044 & 0.007 & & 0.079 \\ 3 & 2.71 & 4.35 & 0.38 & 0.027 & 0.007 & & 0.058 \\ 4 & 4.04 & 1.51 & 0.41 & 0.019 & 0.004 & & 0.036\end{array}$


alloy

GJS-500-

7

GJS-500-

14

GJS-600-

10

GJS-

LowSi 
Pearlite

Batch

Austenization Ferritization

fraction

$\begin{array}{llr} & \text { Cooling } \\ 1900{ }^{\circ} \mathrm{C} / 2 \mathrm{~h} & \begin{array}{l}20^{\circ} \mathrm{C} / \text { hour to } \\ 400^{\circ} \mathrm{C} \text { and then in } \\ \text { the air }\end{array} & 0 \\ & \begin{array}{l}690^{\circ} \mathrm{C} / 4 \text { hour } \\ \text { then in the air }\end{array} \\ 4900{ }^{\circ} \mathrm{C} / 2 \mathrm{~h} & \begin{array}{l}690^{\circ} \mathrm{C} / 0.5 \mathrm{hour} \\ \text { then in the air }\end{array} \\ 5900{ }^{\circ} \mathrm{C} / 2 \mathrm{~h} & 70 \\ 590{ }^{\circ} \mathrm{C} / 2 \mathrm{~h} & \begin{array}{l}\text { Cooling in the air } \\ \end{array} & 100\end{array}$




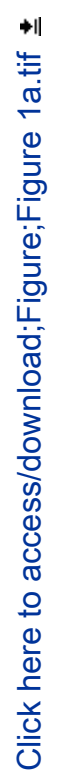
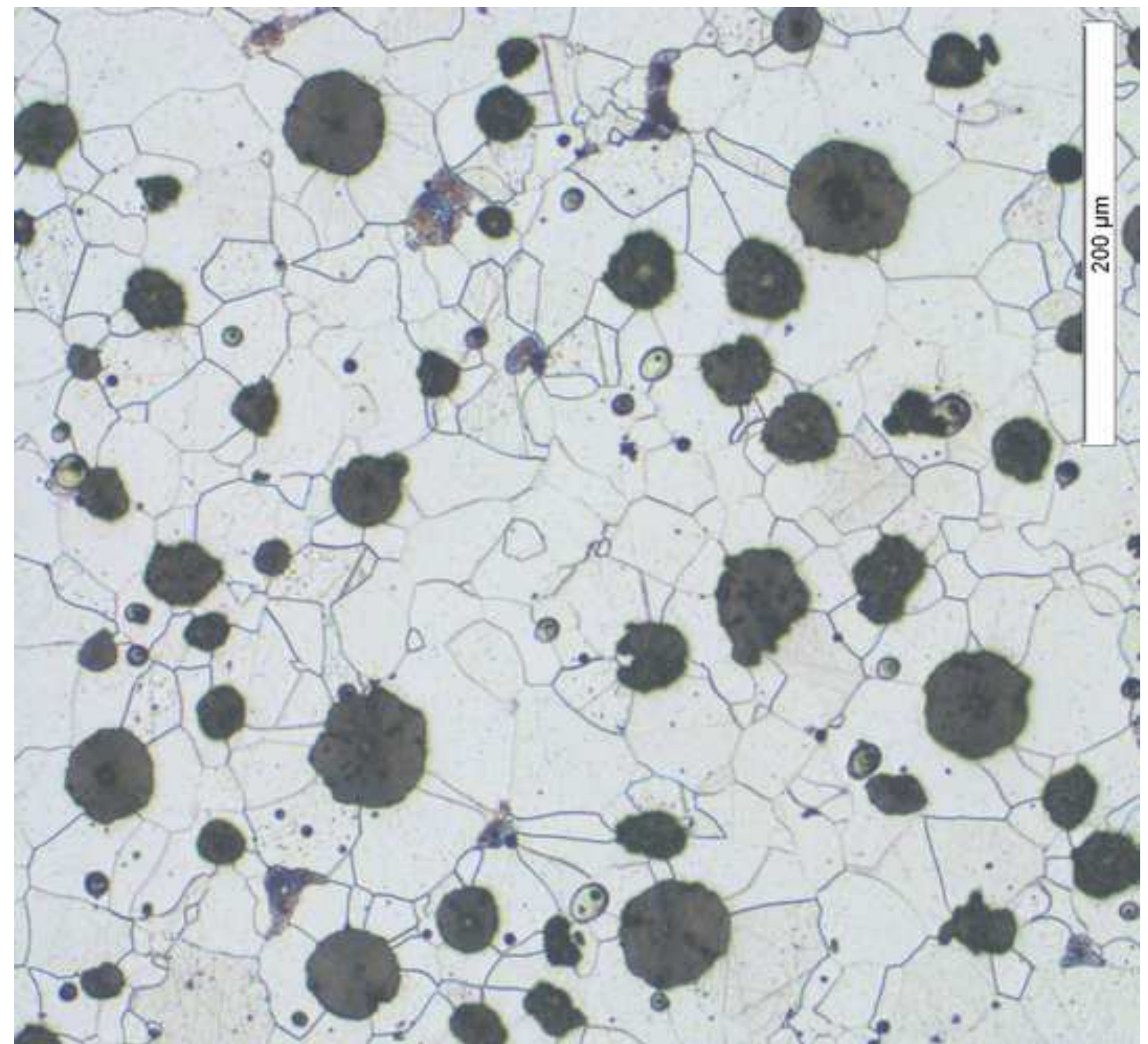

흔 

4 (1) 25. 2 (3)

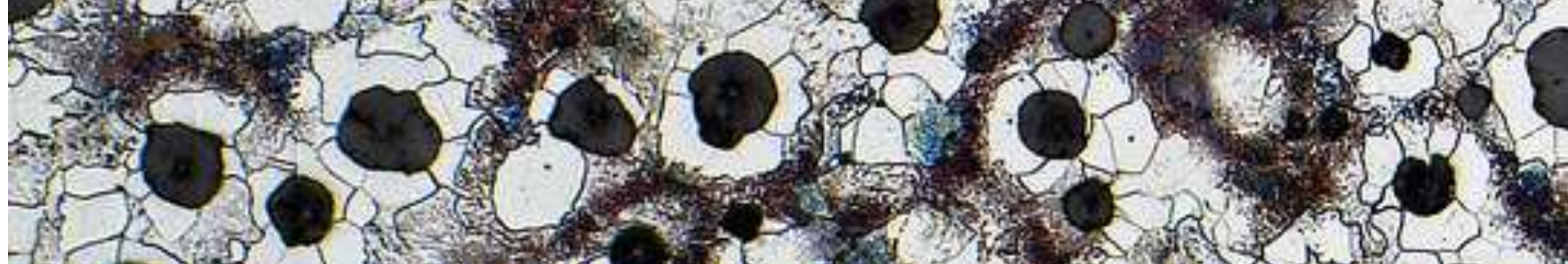

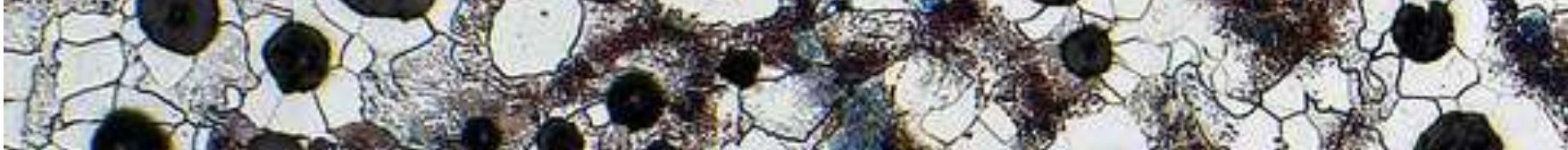

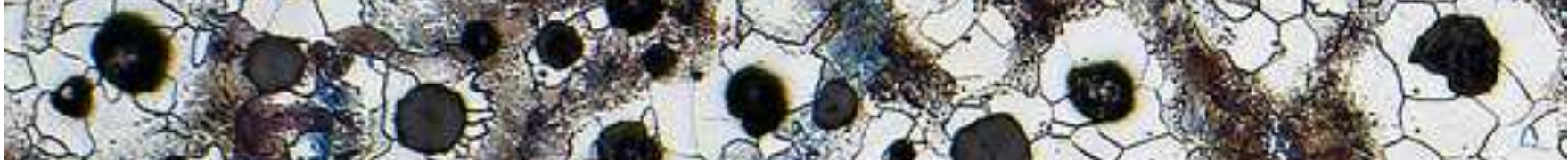

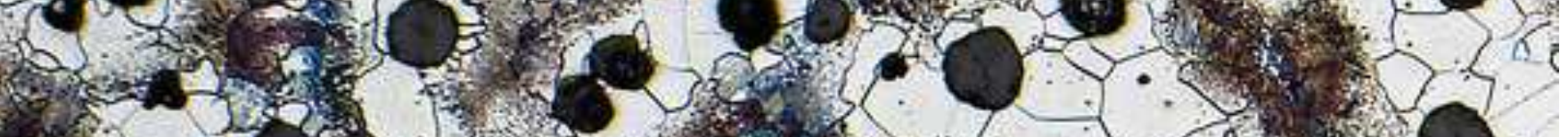

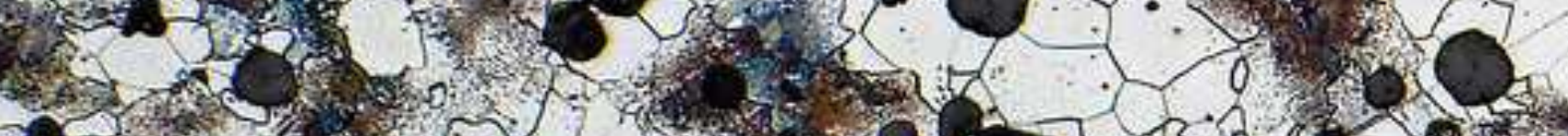

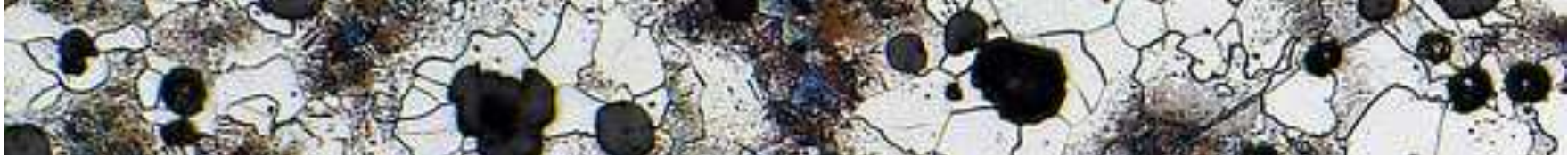




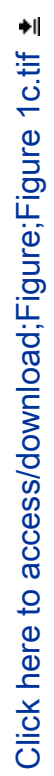
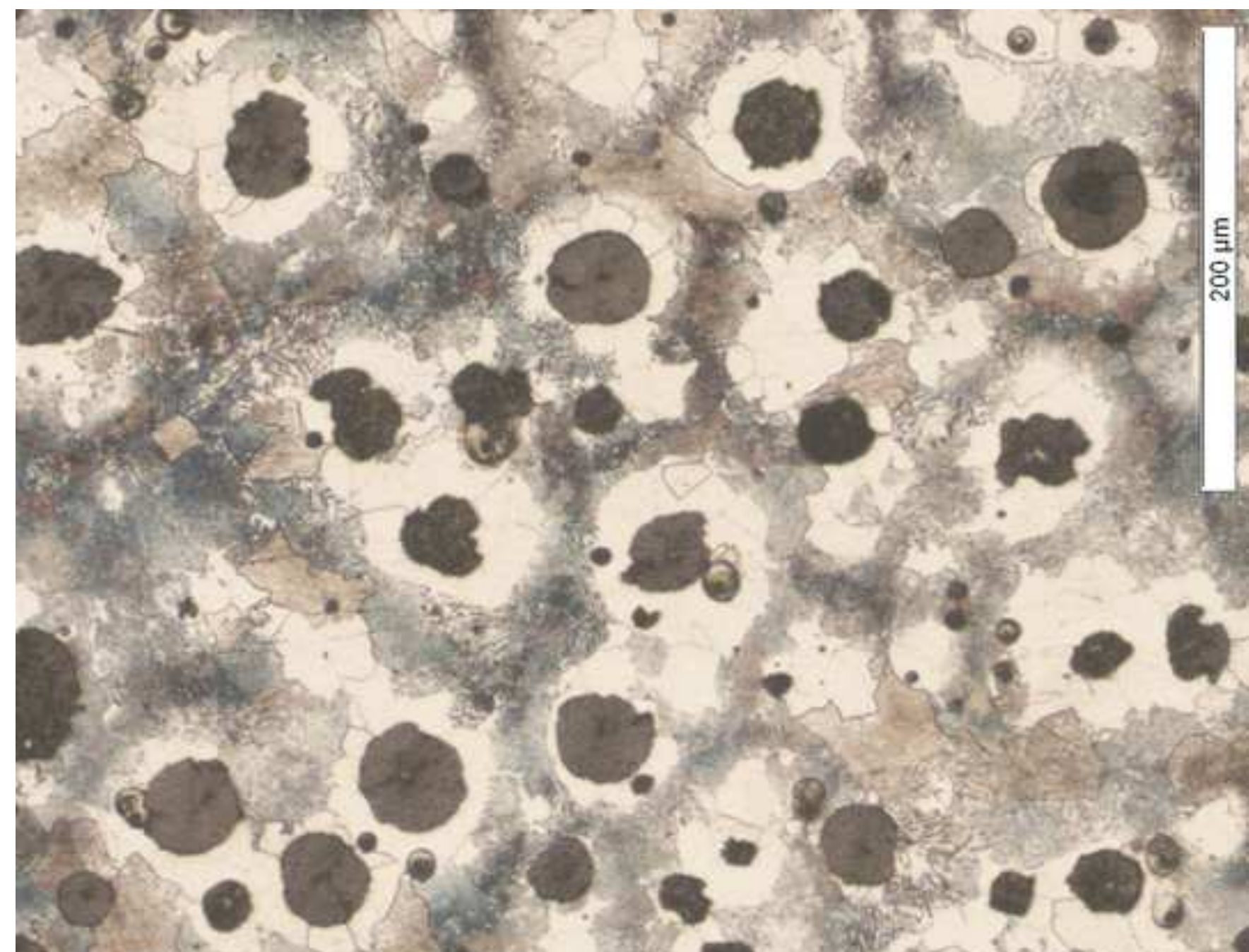

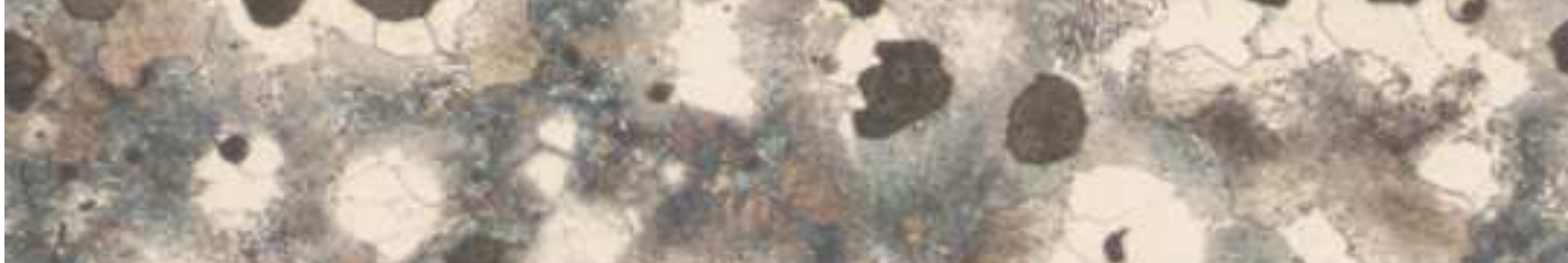

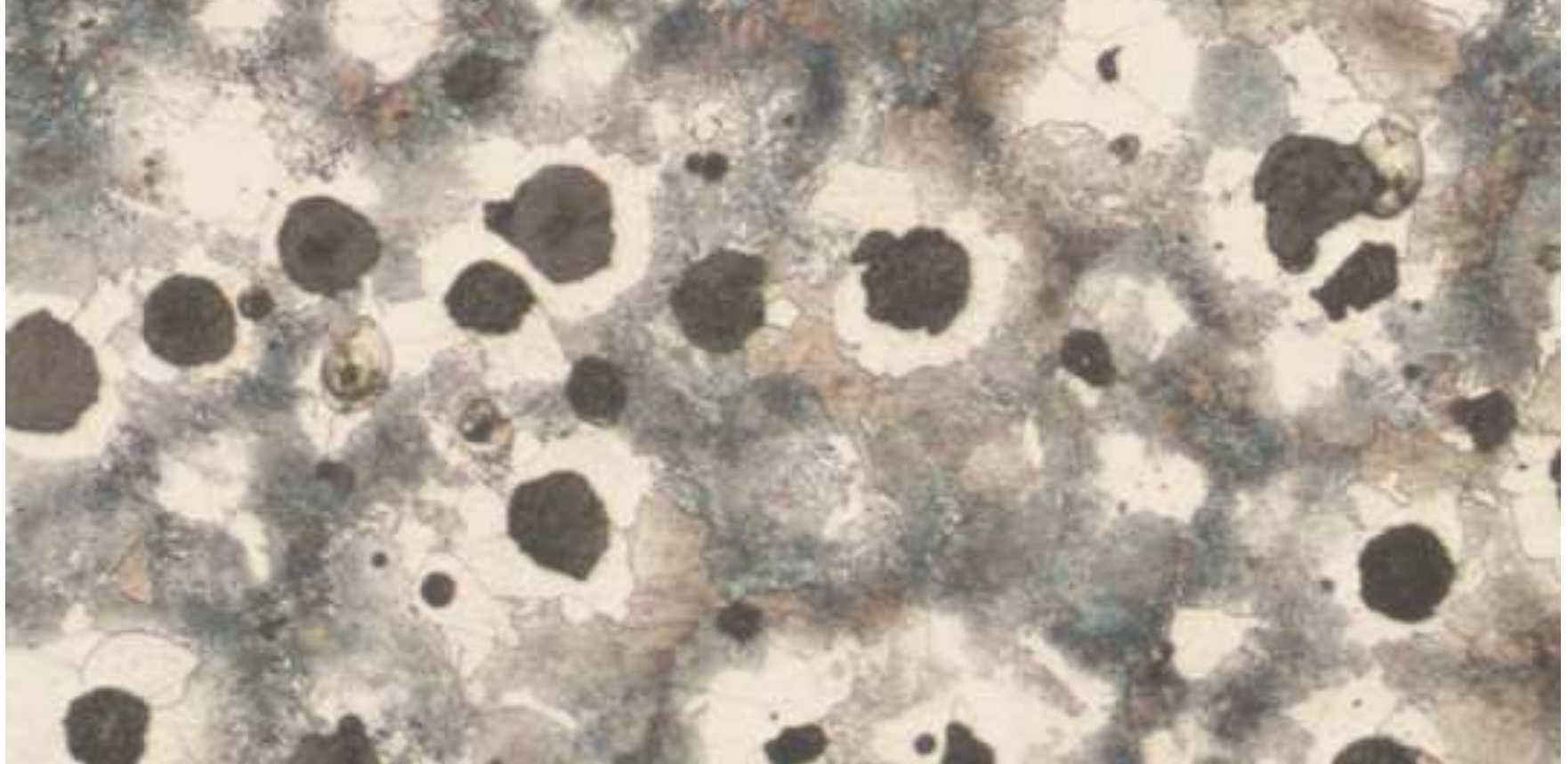

$\frac{0}{0}$ 


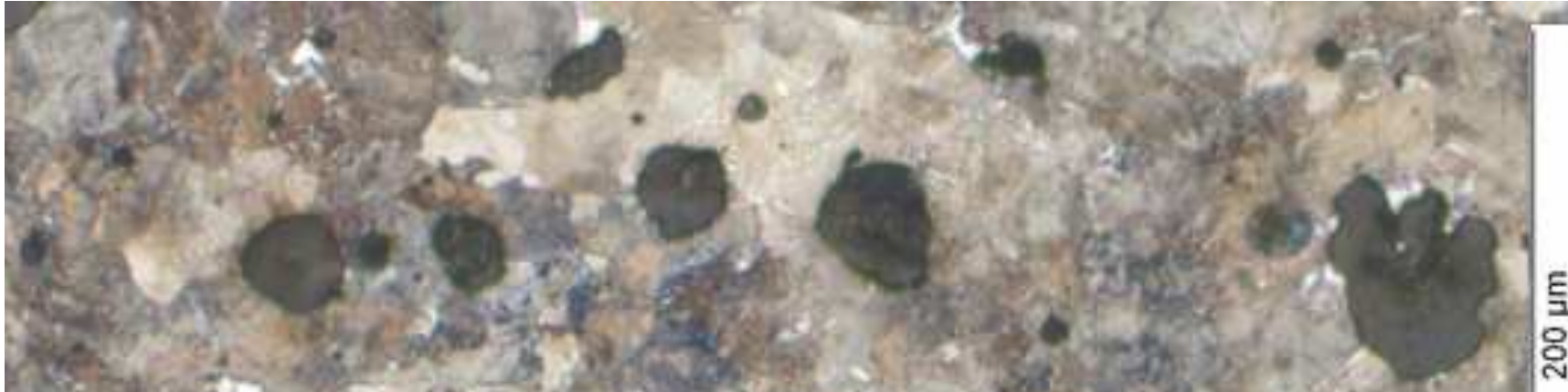

选
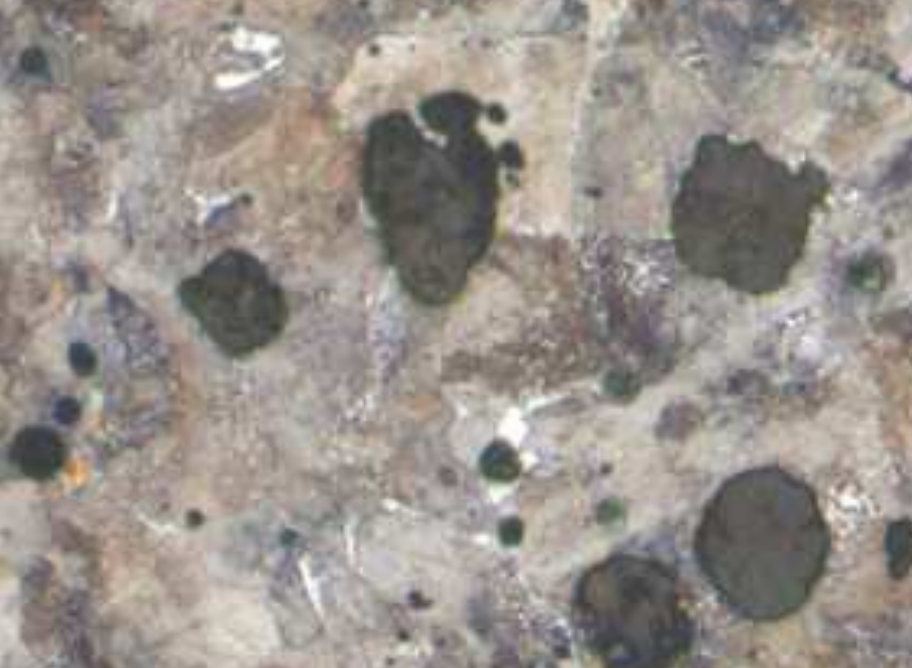

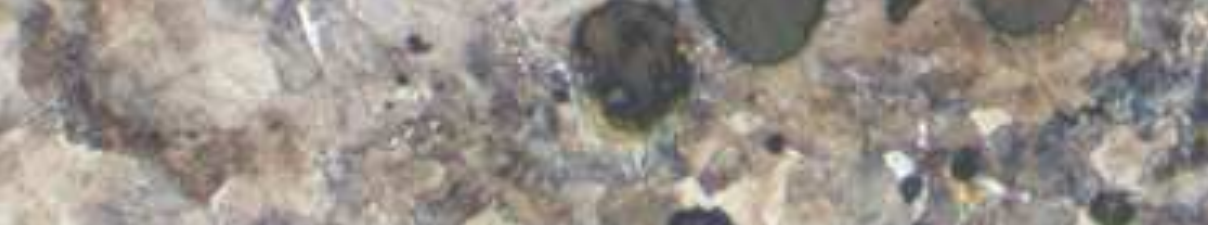
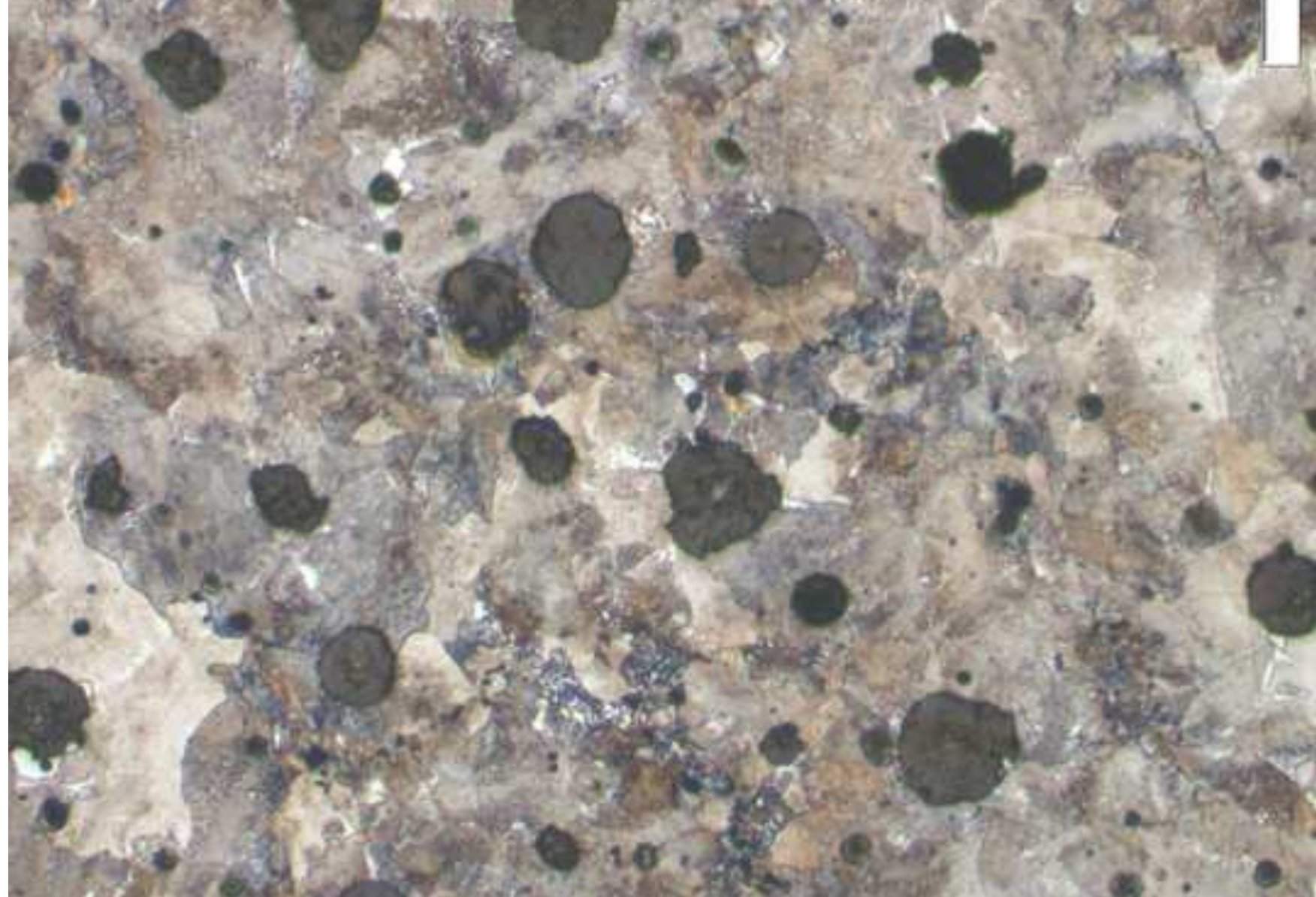

if 


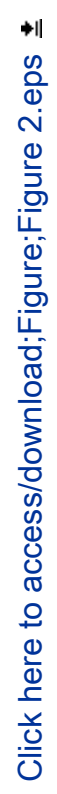

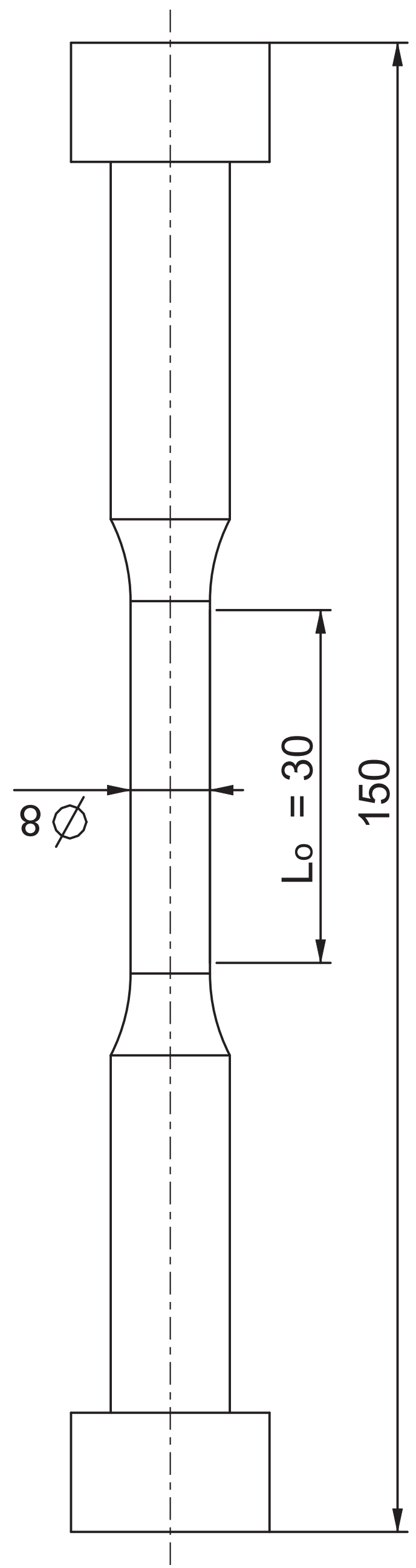

ํㅗㄴ 


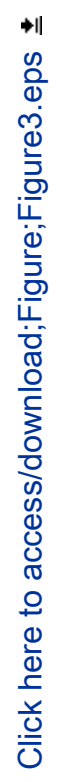
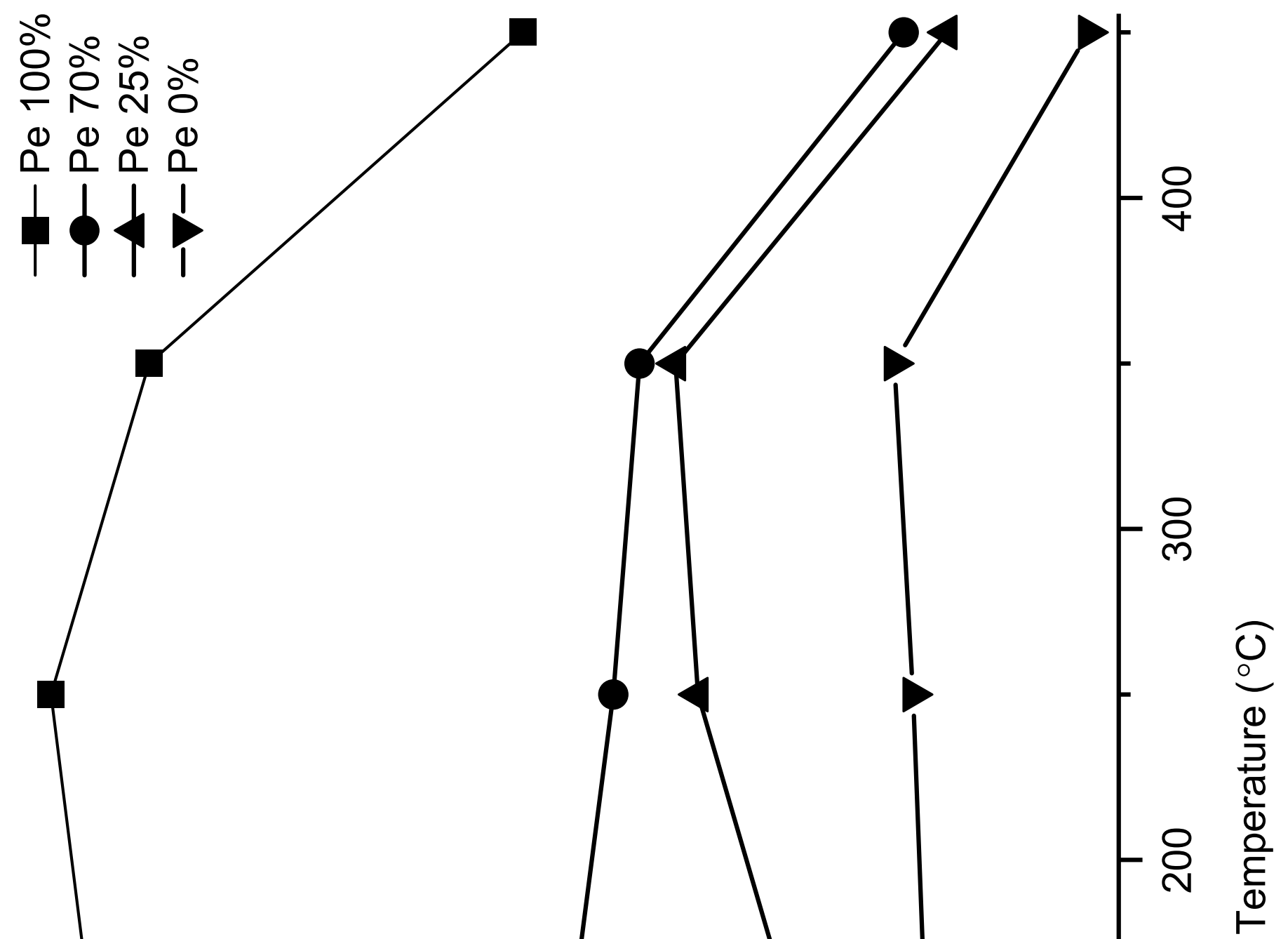

은

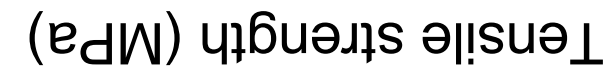




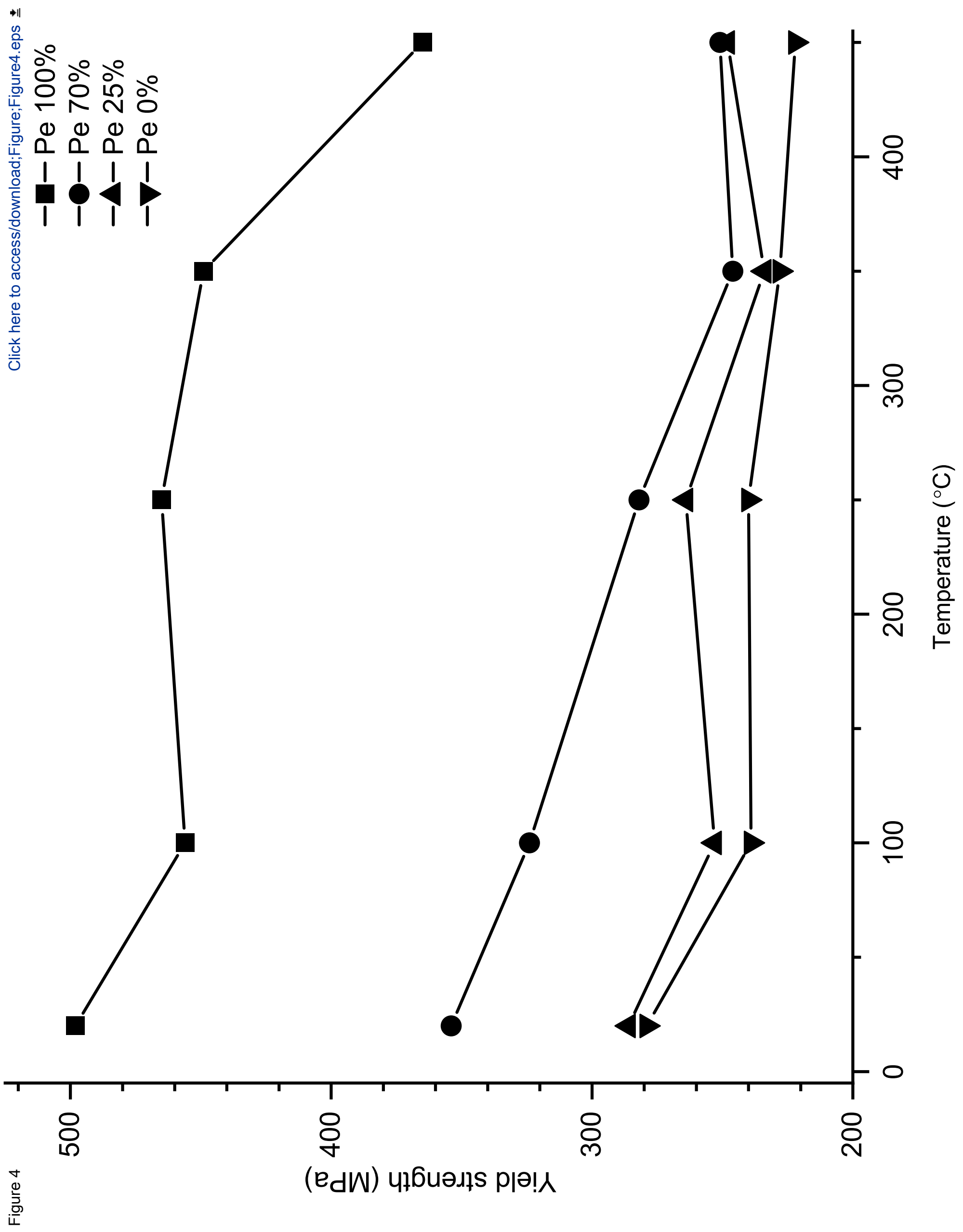




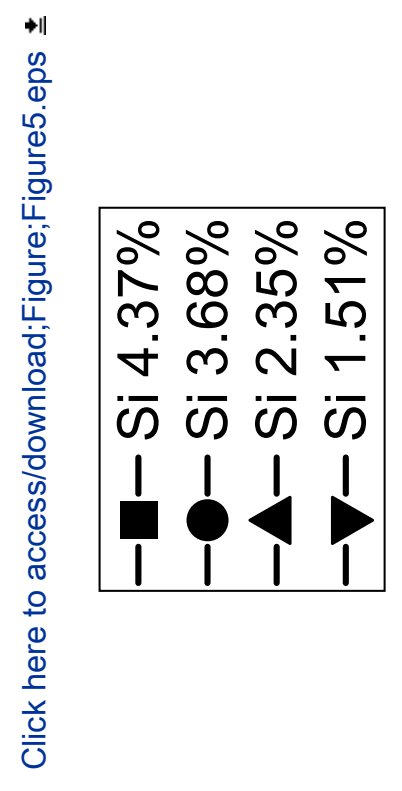




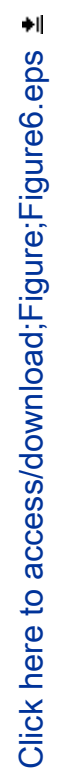
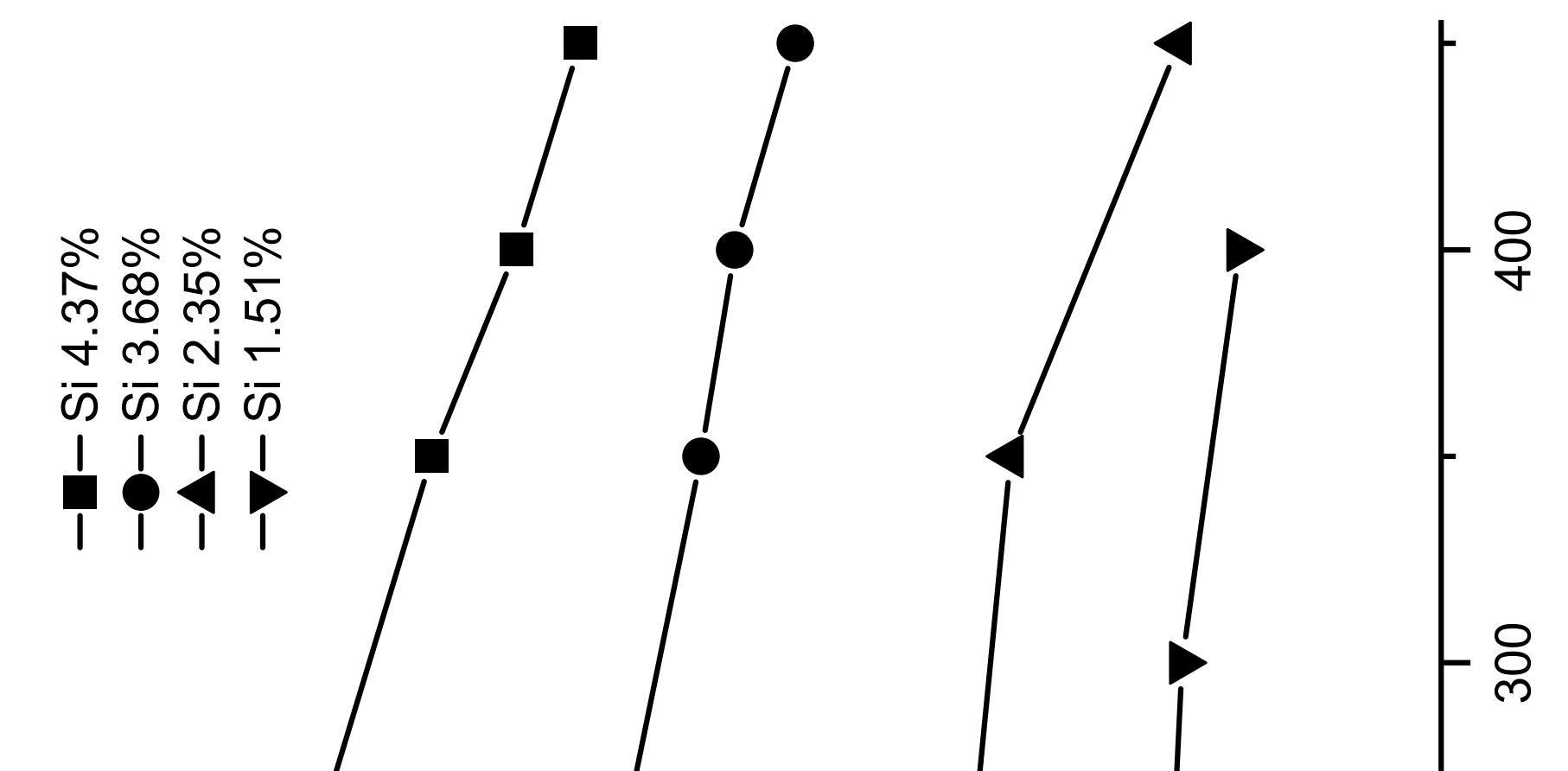


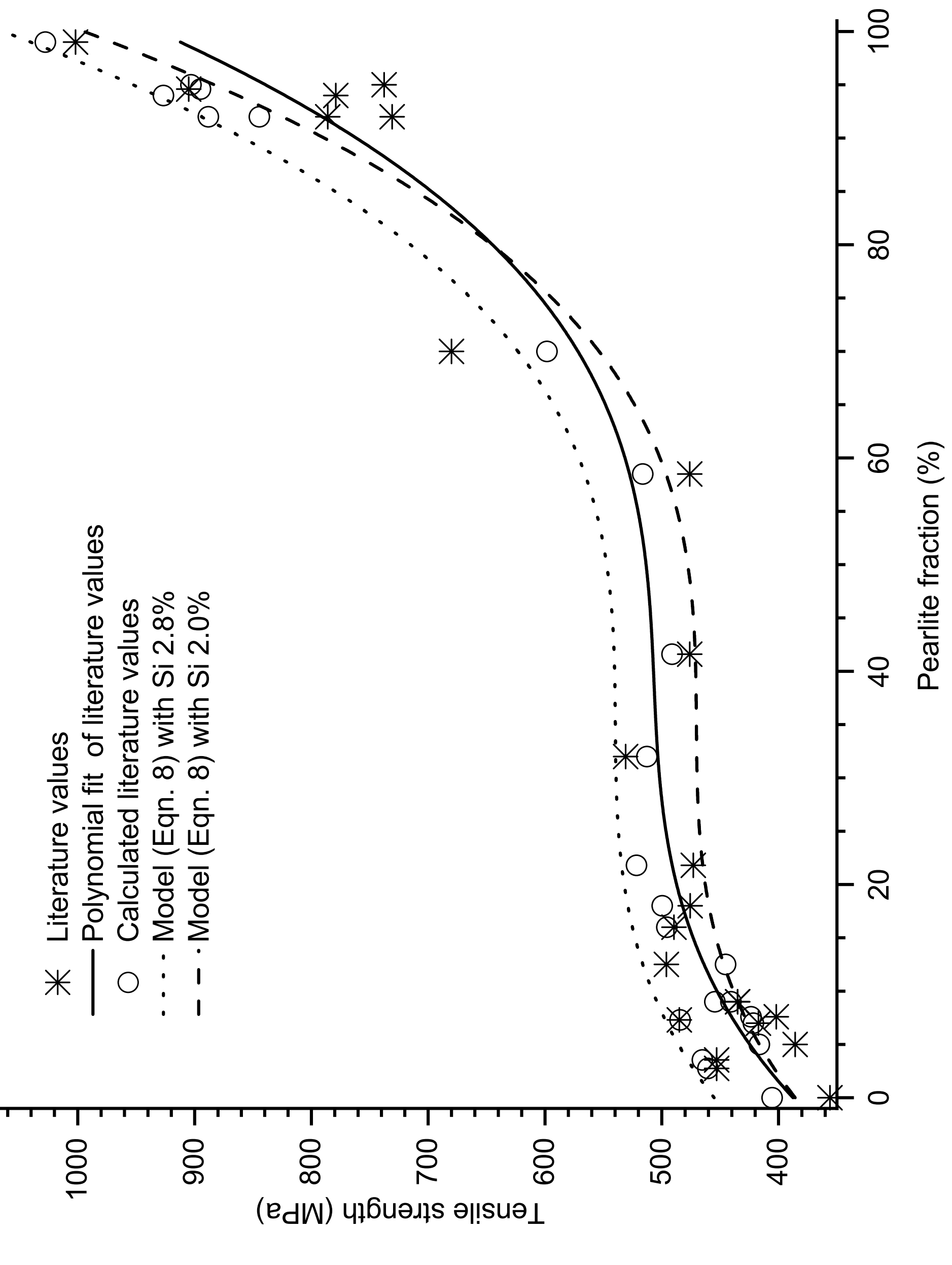


*

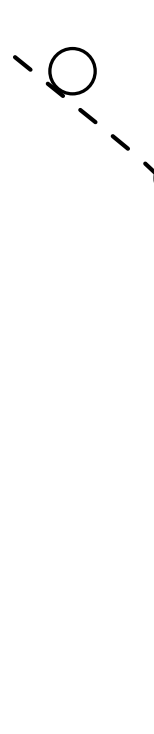

$\frac{\text { D) }}{\frac{2}{7}}$

क \े

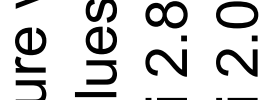

(๖)

$\bar{ত} \bar{\aleph} \bar{c}$

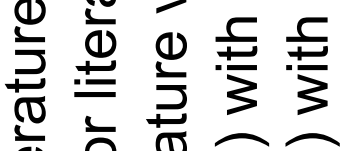

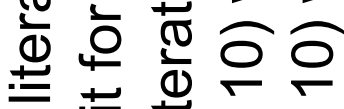

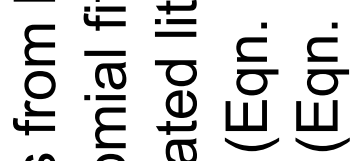

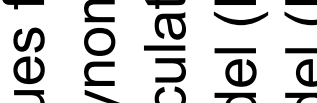

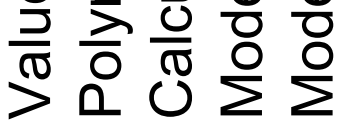

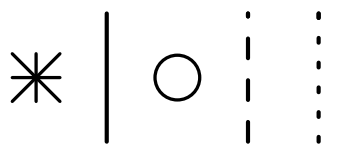

Q

-

、

.

I

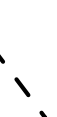

$\because$

$\ddots$
$\ddots$

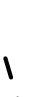

1

$\because$

$\because$

O*

$\infty$

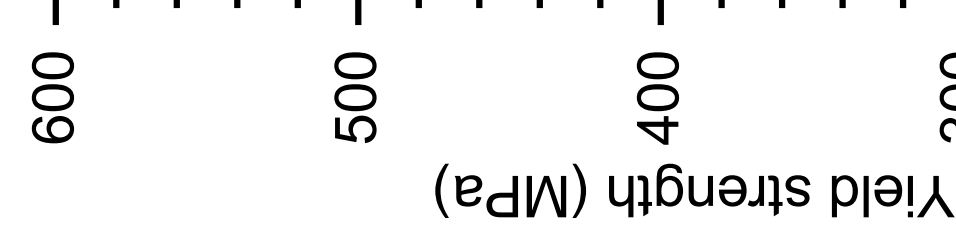


** $\quad$ *
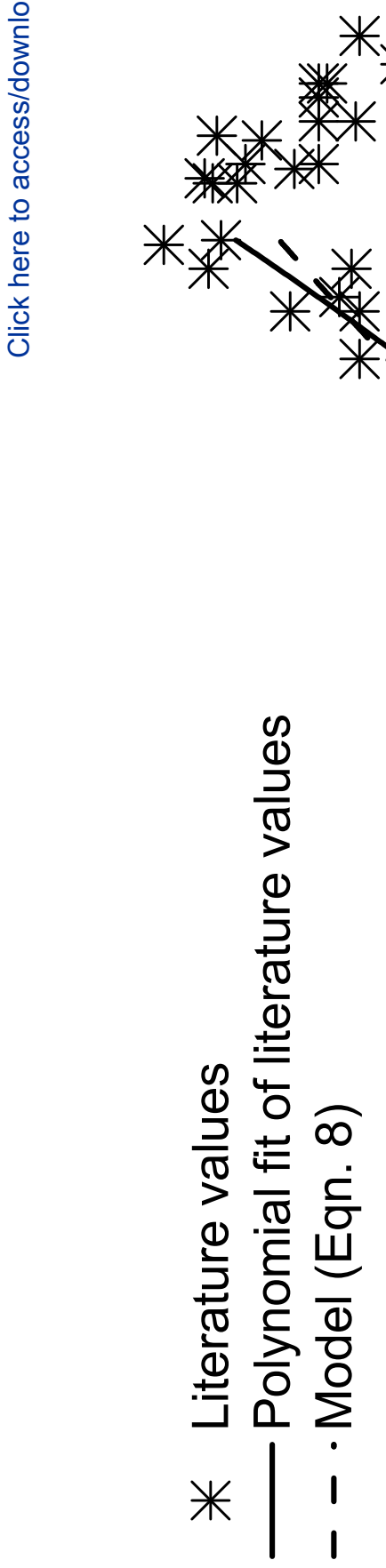

获 **

*

*

1

r 


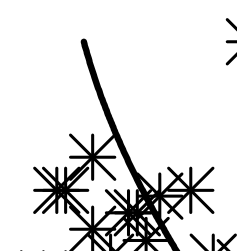

*

米米妆米

y

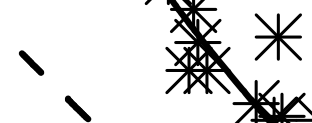

*

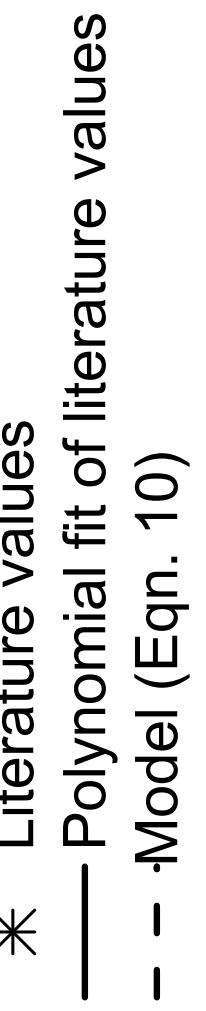

*

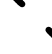

14
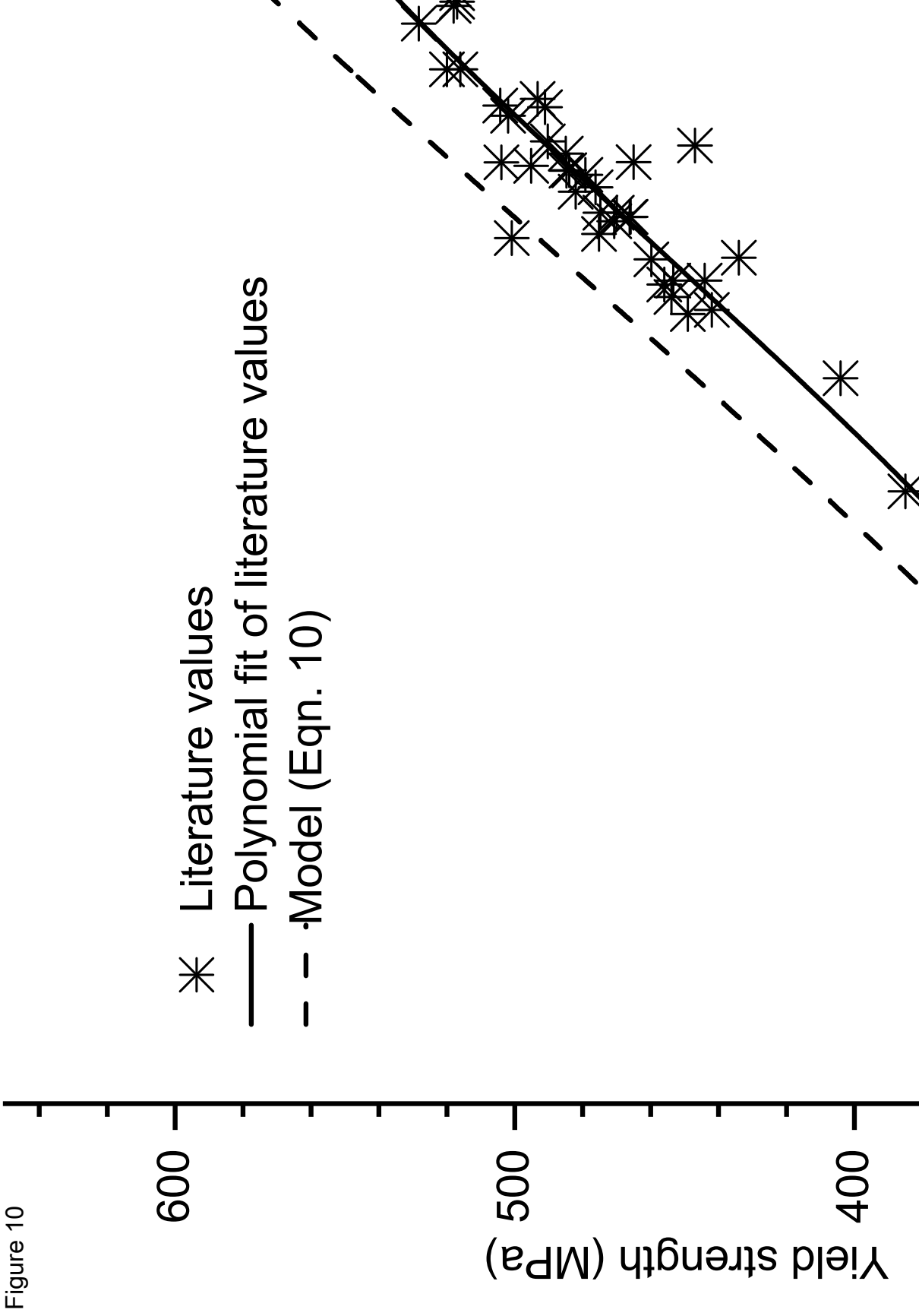